\title{
Hair or Fur Cover
}

National Cancer Institute

\section{Source}

National Cancer Institute. Hair or Fur Cover. NCI Thesaurus. Code C95109.

A description of the quantity or quality of the hair or fur covering a biological entity. 